\title{
Mathematical Metaphysics: Modelling Determinism and Free-Will Along the Lines of Theological Compatibilism
}

\author{
Joseph Ivin Thomas ${ }^{1,2}$ \\ ${ }^{1}$ School of Natural Sciences \& Engineering, National Institute of Advanced Studies, IISc Campus, Bangalore, India \\ ${ }^{2}$ Department of Physiology, East Point Medical College \& Research Centre, Bangalore, India \\ Email address: \\ dr.ivinthomas@yahoo.com \\ To cite this article: \\ Joseph Ivin Thomas. Mathematical Metaphysics: Modelling Determinism and Free-Will Along the Lines of Theological Compatibilism. \\ International Journal of Philosophy. Vol. 7, No. 2, 2019, pp. 93-106. doi: 10.11648/j.ijp.20190702.18
}

Received: March 1, 2019; Accepted: April 28, 2019; Published: July 12, 2019

\begin{abstract}
In this paper, an attempt is made to lay a systematic framework that helps answer a deeply perplexing philosophical question: "Can blind obedience to a set of immutable laws of nature pose a sufficient explanation for all phenomena in the world?" From the perspective of the human person, this question can be re-phrased as follows: "Do the events in a person's life happen because they are pre-determined to do so, or is there some role for free-will to operate?" More succinctly stated, "Is the principle of determinism or the faculty for free-will responsible for the occurrence of an event?" An acceptable answer to these difficult questions must first require a better understanding of what precisely the terms determinism and free-will mean. In religion and mythology, the doctrine of determinism is embodied in an equivalent notion called destiny, which may be defined as a pre-ordained, inescapable, inevitable event. An accident, on the other hand, is a purely random and unpredictable event with neither intent nor design backing its occurrence. Religion holds that there are no such things as accidents and that every event is infused with divine purpose. Paradoxically, religion (Christianity, in particular) holds dear man's capacity for free-will, which is in direct contradiction to the idea of destiny. How can free-will be truly free, if everything is already determined? Science too, is in a similar muddle on the problem of free-will, because it is still unsure whether the universe, the human mind included, runs on a deterministic or an indeterministic basis. After exploring the opinions gathered from diverse fragments of human knowledge (Philosophy, Physics, Neuroscience, Literature, Religion), two novel frameworks that are grounded in mathematical rigor are forwarded which fits both determinism and free-will into a single, indivisible philosophical paradigm.
\end{abstract}

Keywords: Determinism, Free-Will, Causality, Natural Law, Probability

\section{Introduction}

\subsection{The Stance of Philosophy}

There are four major philosophical positions in the determinism-free-will debate. Two of them, namely Hard Determinism and Metaphysical Libertarianism, regard determinism and free-will to be mutually incompatible notions $[1,2]$. What this means is that, if determinism is true, then free-will is not possible and if free-will is possible, then determinism is not true. Philosophers who subscribe to either of these positions are called Soft Incompatibilists. The position of Hard Incompatibilism holds that free-will is irreconcilable with both determinism and indeterminism [3]. For this reason, philosophers belonging to this camp, are referred to as Pessimistic Incompatibilists. The position of
Compatibilism asserts that free-will is compatible with determinism [4]. To a Compatibilist philosopher, the determinism-free-will debate is just a false dilemma. The argumentation of this essay is rooted in Compatibilism, or rather a more specific variant of it called Theological Compatibilism. But before delving into a detailed exposition, some of the scientific and literary details surrounding the general debate is first furnished. At the end of this essay, a formal analysis is carried out and two distinct mathematical models are forwarded that effectively merge the twin notions into a single paradigm.

\subsection{The Stance of Physics}

With the advent of Newtonian Physics, the Universe came to be viewed as a clockwork, mechanistic, materialistic system, wherein the occurrence of every event can be predetermined 
from the knowledge of initial conditions. For instance, if the velocity and position of a moving particle is known at a particular instant, then using the laws of motion, its velocity and position can be computed for any other instant. According to this paradigm, there is no place for such a thing as free-will or deliberate self-made choices, but only an inevitable destiny or pre-determined outcome for all things. But by the end of the third decade of the $20^{\text {th }}$ century, Quantum Mechanics with its central tenet - the Uncertainty Principle demonstrated that there exists a fundamental limit to what can be known about the physical world. The principle states that it is impossible to possess an exact knowledge of a particle's position and velocity simultaneously. In fact, the more accurately you know one, the less accurately you know the other. Thus, a particle cannot be said to be here or there and moving with this or that velocity without invoking some degree of uncertainty in both those parameters as well. We can only speak in terms of the probability of finding a particle in this position and moving with that velocity, at a particular instant of time. In a sense, the particle can be said to exist everywhere at once, (omnipresence?), with a spatial distribution of probabilities that extends to infinity in all directions. However, the likelihood of finding it at one particular place may be greater than in all other places. The introduction of randomness into Physics (or rather, the departure of Physics from determinism) at such a fundamental level, has created a sort of portal for free-will to operate. Perhaps, the earliest source that can be found in the literature on free-will that can be said to subscribe to this view-point is the book Miracles: A Preliminary Study by CS Lewis [5].

\subsubsection{Determinism in Classical Physics}

There are different versions of the doctrine of determinism, depending on the context in which it is used. The two versions, pertinent to this essay are Causal (or Physical) Determinism and Theological Determinism. Causal Determinism, holds that every event in the physical universe has a cause, which precedes it. The picture of a series of upstanding dominoes placed closely beside each other is often invoked to illustrate this principle. When the first domino is nudged forwards with the finger, the one infront of it gets knocked over, and that one goes and knocks over the next domino infront of it, and so on. Each domino falls, because the one preceding it, caused it to fall. This is true for all the dominos in the series except for the very first domino, which had fallen because some agency gave it a first push. If each falling domino is considered an event, then it is clear that there is an ordering in time for all the events, i.e., each event is preceded in time by another event. Each preceding event is called a cause and each proceeding event is called an effect. Thus, it can be said that each effect serves as a cause for the subsequent effect. The entire series of dominos represents a causal chain of events, and it is this chain that forms the underlying basis of determinism. A key feature of the causal chain is that no effect is without its cause, except for the very first cause, which must necessarily be causeless if it is to initiate the chain. But can there exist any such thing as an uncaused cause? For an event to have no cause would mean that it has no beginning in time either, because a beginning would necessitate another cause to bring it into existence. The only conjectured entity that fits this dual description of having no beginning in time and no cause to bring it into existence, is God. Hence, God is the first cause or the uncaused cause or the causeless cause. The ancient and medieval philosophers, like Aristotle and St. Aquinas amongst many others, subscribe to this viewpoint [6]. We can conclude that for the doctrine of determinism to be true in a universe of a finite age, the existence of God must necessarily also be true.

\subsubsection{Indeterminism in Quantum Physics}

If determinism is false, then indeterminism is true, i.e., a cause need not precede an effect. But this would necessitate the existence of uncaused causes, which are events that can spring into or out of existence in the absence of any prior warranting conditions. If the creation of the universe is one such uncaused cause, then the existence of a creator God is unnecessary. One well known example of a physical event without a preceding cause (i.e. an uncaused cause) is the phenomenon of quantum tunneling, where an electron can effortlessly burrow through an energy barrier that Classical Physics prohibits. Quantum Mechanics furnishes a beautiful mathematical explanation for this and other similar bizarre subatomic-level phenomena that is grounded in Probability and Statistics. However, a precise causal explanation or a material mechanism eludes the theory. The physicist David Bohm gives an elaborate account on this subject in his book Causality and Chance in Modern Physics [7]. The dominos metaphor described above may be adapted in the context of indeterminism as follows: an upright domino can spontaneously fall to the ground in the absence of any physical initiating event that precedes it, like the impact from another falling domino or air currents or radiation pressure etc.

\subsection{Bridging the Determinism-Indeterminism Divide}

If, however, it is insisted that a cause be attributed to the physically uncaused fall of the domino, then it must be necessary to invoke a non-physical, transcendent agent permeating all matter and space that willed the domino's fall. By postulating the existence of such an agent, the doctrine of determinism can be preserved, since every event will then have a preceding cause, including those events that are not caused by a physical agency. Moreover, the doctrine of indeterminism is also preserved, since it is impossible to possess foreknowledge of a transcendent agent's will. And in the absence of complete knowledge, it is necessary to resort to the mathematics of randomness (Probability Theory) in order to make a reasonably reliable prediction of the occurrence of events. So, if such a transcendent agent possessing free-will exists, then both determinism and indeterminism are true.

\subsection{The Stance of Neuroscience}

Mainstream neuroscientists assert that it is a stream of electrophysiological and biochemical events in the brain that finally culminates in an individual making a conscious 
decision. Experiments have shown some of these events to be identifiable in advance of the subject becoming aware of his own choice. In the case of the famous EEG experiments of Benjamin Libet, the event referred to, is an electrical signal called the Readiness Potential [8]. These experiments seem to conclude that the brain decides before the subject consciously decides, which would mean there can be no such thing as free-will. However, it should be noted that the methodologies adopted in these no free will studies are still highly controversial. It's also uncertain whether their interpretation can extend to more general contexts outside the controlled setting of a laboratory and into daily life. The plausibility argument for free-will has suffered much disregard in neuroscience, owing to its materialist foundation. According to the mainstream, the mind should be viewed as nothing more than a natural phenomenon, an outcome of a complex cascade of neural activity in the brain, with molecules and membranes playing the role of prime actors. The neuroscientist, guided by this rule of thumb, sees no reason to invoke any agency outside the contents of the cranium to explain the working of the mind. What is referred to as the ghost in the machine hypothesis (a. k. a. Cartesian Dualism) is simply rejected as unnecessary. However, a turn in the tide of opinion has begun in recent years that questions the sufficiency of neural activity per se for human cognition. Quantum physics with its central doctrine of indeterminism may have something substantial to say about brain processes and is likely to trigger a revolution in our understanding of the mind, in the near future. The works of Roger Penrose and Stuart Hameroff offer a potential first step forward in this direction $[9,10]$. One predictable consequence of these efforts will be the elevation of free-will from its current status as a mere illusion to an established fact.

\subsubsection{Determinism in Neuroscience}

As stated above, neuroscience is founded on the tenet of material monism, and neuroscientists adopt a strictly deterministic approach to their discipline. They promulgate that it is the biophysical-biochemical processes, and the wiring and firing of neurons in the brain, that is responsible for the decision-making process. Hence, conscious decision making is said to always lag behind subconscious information processing in the brain. The causal chain for the decision-making process can be sequenced as follows: Information $\rightarrow$ Brain $\rightarrow$ Conscious mind makes a choice $\rightarrow$ Brain $\rightarrow$ Body enacts decision. The conscious mind (the place or thing in which one would expect the seat of free-will to reside) makes a choice only after some amount of prior information processing has occurred in the brain.

\subsubsection{Indeterminism in Neuroscience}

There is however, atleast one scenario wherein the above causal chain may be missing an important element. It is a common human experience, that when the same environmental stimulus is presented to the sensory faculties on two different occasions, the same brain may end up making different choices. But if the brain operates on a deterministic model, it is expected to yield the same outcome every time the same stimulus is presented. This has to mean that the multitude of internal processes going on in the brain, compel it to operate to some degree in an indeterministic fashion. It could even be that the brain which is necessary for cognition to occur, may not be wholly sufficient for decision making. Also, there are two assumptions the deterministic paradigm makes, neither of which need be true. The first is that, the conscious mind can assert no influence of its own in the decision-making process. It acts strictly as just one of the relay stations during information processing in the brain. The second is that, the only portal of entry for information from the outer world into the conscious mind is the brain. Both these assumptions can be done away with by postulating a faculty that operates independently of the brain and which is itself not subject to the causal argument. That is, it can cause events to occur in the brain, but is not itself caused by events occurring in the brain. A similar idea has been previously asserted by the neurophysiologist Sir John Eccles and the philosopher of science Karl Popper in their Interaction Dualism theory [11]. It is precisely this faculty that can be referred to as free-will. However, the seat of origination of free-will, if it exists, is still a mystery. Neither the scientist nor the philosopher dares to claim knowledge of where it stems from. To the theologian, however, free-will is an inherent trait of God. By virtue of the scripturally inspired tenet that man is made in the image or likeness of God, free-will is one of man's imbibed traits. Free-will, when viewed in this light, shares the same status as that of any other given in physics (e.g. charge, mass, spin etc.), whose source of origin is unknown and is simply taken for granted. The philosopher David Chalmers holds a similar view on consciousness [12].

\subsection{Metaphysical Libertarianism}

The above non-causal argument made for free-will favors the philosophical position known as Metaphysical Libertarianism. According to this doctrine, free-will can over-ride physical causality. Plausible mechanisms have been proposed to describe how this may happen, in the form of Two-Stage Models [13]. A Three-Stage Model of free-will is proposed here, that bears a close semblance to, but is subtly different from the Two-Stage Models. In the first stage, the alternative possibilities for action are generated in the conscious mind, indeterministically. In the second stage, the agent's will makes an evaluation of the best single action from amongst those possibilities, again indeterministically. Finally, in the third stage, the choice made by the agent's will is conveyed to the brain by influencing various internal processes, (which operate deterministically), leading to the performance of action. To visualize the Three-Stage Model with the help of an analogy, think of the conscious mind as a small green circle in the plane of this paper (see Figure 1). Then represent the alternative possibilities for action by equally spaced multiple black arrows emerging from the green circle and pointing in all possible directions. Free-will can be represented by a single red arrow that visits each potential action in the same manner as the second hand of a clock visits 
each minute on its face. Once an agent's free-will has made a specific choice of action, the red arrow comes to rest on top of the corresponding black arrow, consequent to which the green circle gets spatially displaced in that direction. The displacement of the green circle to its new position in the plane of the paper, represents the internal processes of the brain operating deterministically to execute the specific choice of action.

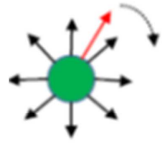

Stage-1

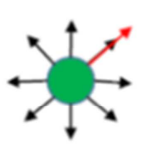

Stage-2

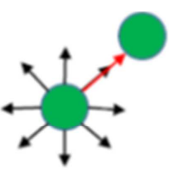

Stage-3
Figure 1. Three-Stage Model of Free-will.

\subsection{The Stance of Literature}

The great determinism-free-will debate can trace its origins, to the mythological literature of the ancient Greeks. Sophocles play "Oedipus: King of Thebes" best exemplifies how both these opposed perspectives can operate in collusion [14]. The story goes as follows: Oedipus was at birth prophesized, to take the throne after killing his father (the King of Thebes) and marrying his mother (the Queen of Thebes). This oracle was directly conveyed to the King, who then made arrangements for baby Oedipus to be killed. But despite his extreme efforts to avert potential disaster, all that was foretold eventually comes to pass. At the onset of the drama, it appears as if free-will is fully operational, with independent choices being consistently made by different players. But very gradually it becomes clear that fate is subtly at work from start to finish and not free-will. In fact, free-will seems to be reduced to a time constrained mirage, masking the truth about a much deeper layer of reality. Every decision made throughout the play only draws the predicted disaster closer, not further away. The story cleverly demonstrates how even the choices we think we make freely and independently without coercion or counsel, are predetermined to direct us towards some inevitable destiny or fate that is assigned to us beforehand.

\subsection{The Stance of Religion}

The theology underlying the Judeo-Christian Faith is chosen as a reference for what religion has to say on the subject. No doubt, other religious traditions may well have their own takes, but they shall not be explored here. Three types of biblical accounts are analyzed in turn, very briefly. The first concerning the lives of particular individuals, the second regarding the exodus of the Hebrew people from the land of Egypt where they were held captive for 430 years, and the third, about the end-times prophecies. Finally, a theological proposal for the origin of free-will is made.

\subsubsection{The Lives of Particular Individuals}

i. The Lives of Adam and Eve

The first and second chapters of the biblical book of Genesis describes the Fall of Man. Adam and Eve - the first man and woman - were commissioned by God to look after the newly created Garden of Eden. They were told that they could eat the fruit from any tree in the Garden except from the tree of the knowledge of good and evil. God further warned them that the day they eat from it, they would surely die. The story symbolizes the Creator's allowance for free-will to operate and His non-interference with the decision-making process. They were granted the freedom to choose for themselves, to either eat or not eat of the forbidden fruit. They could either attune their free-will in perfect alignment with that of God's will or choose to do otherwise. Besides an allegorical reference to free-will, the Garden of Eden story also serves to symbolize two peculiarities of the human condition. The first is man's innate desire to be independent of God and the second is to achieve a God like stature by becoming like Him. Independence from God would mean that man no longer has to worry about whether his actions please or displease God. The only person he need please is himself. Man, in that sense would become a source of happiness unto himself. The inclusion of God into the picture would only detract from this. To be like God would mean to know all, be all and do all without the fear of reprobation. These qualities are exclusive to God's nature and no thought can be more enticing for man than the possibility of outshining his own Creator. Adam and Eve decided to cave in to these innate desires and exercise their free-will in direct disobedience to God's warning. The consequence was just as promised, with death entering the world. History is one long account of how mankind has ever since been fending forces, both natural and otherwise, that threaten to take life.

\section{ii. The Life of Abraham}

The Story of Abraham, in the Bible succinctly shows how certain pre-assigned events that are destined to happen in the future, will come to pass no matter how unlikely they may seem to be in the present. When God first called upon Abraham while he was living in Ur, Mesopotamia, he was 75 years old. The Lord instructed him to leave his father's home and go to the land that would be shown to him. God then blessed him and promised to make a great nation out of his offspring. He later promised to make him the father of not one, but a multitude of nations and that their numbers would be as numerous as the stars in the sky and the sands in the seashore. This promise was made when Abraham and his wife Sarah were well past child bearing age. And by all human standards it would seem a ridiculous thing to hope for. But Abraham believed and had faith in what God could do. Bible Scholars place the approximate year on the world timeline when the couple lived, to be around 2000 BC. More than 4000 years later, Abraham is today celebrated as the Grand Patriarch of three of the great religions of the world, namely Judaism, Christianity and Islam. Their adherents, are spread out over the six inhabited continents and collectively constitute more than half of the world's population. This would number to approximately three and a half billion peoples by current estimates. Despite the myriad differences in the faith and practices of the three religions and the frequent clashes that have kept cropping up between each sect through history, they 
all nonetheless zealously revere and refer to him in their respective traditions as Father Abraham.

iii. The Life of Joseph

Jacob, the grandson of Abraham, had twelve sons. Among them was Joseph, the eleventh child, who was Jacob's personal favorite. Whenever the older brothers were up to some mischief, Joseph would promptly report it to his father, which earned their collective disdain. Jacob made no effort to conceal his favoritism towards Joseph and on one occasion, he even got his whole family together to witness him gifting Joseph with a special robe. This event aroused much jealousy and hatred amongst the brothers an added to all of this, whenever Joseph had a peculiar dream at night, he would promptly describe it in vivid detail to his brothers. In one such dream, he saw himself with all his brothers tying bundles of grain, and all of a sudden, his bundle stands up, while all the other bundles gather around and bow down low before his. In another dream, he saw the sun, moon and eleven stars bowing low before him. The meaning of these dreams was plain and clear to his brothers. It absolutely infuriated them that the second youngest in the family should have the audacity to see himself seated in a position of authority above them all. What began as jealousy gave way to raw malice and they plotted to have Joseph killed. They would have succeeded in their plans had it not been for the intervention of Judah (one of the eleven), who suggested to sell him for a price, as a slave instead. His life was thus spared, at the cost of a demotion in station, from the comfort of living by his father's side to the mercy of a slave trader's whip. Though marred by a long string of ups and downs including a false conviction of rape and serving time in a dungeon, Joseph trusted in God through all his tribulations, public humiliation and personal shame. His trusting was not in vain. When least expected, he gets miraculously appointed as Egypt's Prime Minister, second only to Pharaoh in authority. Joseph was only 17 years old when sold into slavery and 30 by the time he was appointed to high office. By his 38th year, all the events predicted in his boyhood dreams came to pass, including the reunion with his family after a separation of nearly 20 years. He was no longer the former young boy who could be easily bullied and pushed around by his older brothers, but a man of immense power and influence, to be feared and respected by all.

iv. The Life of Gideon

Gideon was a very ordinary man belonging to the tribe of Manasseh. He possessed none of the qualities that are often seen in men of great leadership, like bravery or determination. Yet it is interesting to note that God chose him to rescue Israel from their enemies - the Midianites. These warring peoples would frequently plunder and pillage the Israelites, leaving them to starve or run to the hills for refuge. It was during these hard times that an angel of the Lord appeared before Gideon and addressed him 'O, Mighty man of valor'. Ironically, it was while he was busy hiding away some leftover grain in his father's winepress, so that it wouldn't be looted. The angel then commissions him to lead Israel to victory against the Midianites. Feeling understandably a little disoriented by both the encounter and the commission, he takes a quick stock of his immediate situation and asks the angel how the weakest member of the weakest family in the tribe of Manasseh was going to carry out such an impossible task. The angel reassures him, that God would be by his side all the way. As events unfold, the timid and fearful Gideon transforms into a mighty military general who finally defeats Midian completely. There was peace in the land for the rest of Gideon's 40-year reign as Judge over Israel.

v. The Life of Jesus

Jesus is perhaps the most enigmatic figure in all of history. No man can be said to have had a greater impact on the world than this Jewish son of a carpenter, from Nazareth. Brilliant teacher, passionate preacher, astute philosopher, pragmatic spiritualist, sublime moralist - these are just a few of the many ways to understand him, on the surface at least. While much about his life is shrouded in mystery, like the unaccounted 18-year interval between the ages 12 to 30 years old, a lot is known about the circumstances surrounding his birth and also the 3 -year interval spanning the ages 30 to 33 years old. It appears that everything about the man was predestined. $\mathrm{He}$ had a mark on his head from the day that he was born to fulfill some great purpose. The greatest purpose, as was foretold by the Prophets of the Old Testament, was to suffer and die as an atonement for the sins of mankind, followed by resurrection three days later. But to get to that point, he had to pass through several situations wherein free-will had an undeniable role to play. A few of these instances include:

a. The devil tempting him three times in the wilderness and he does not yield;

b. When a crowd of followers forcefully try to make him King, he just slips by;

c. In the garden of Gethsemane, he prays that 'the cup be passed', but immediately thereafter confesses that it is the Father's will and not his own will that was important;

d. When the soldiers come to arrest him at midnight, he does not offer the slightest resistance;

e. When the court officials question and jeer at him, he remains silent;

f. While yet on the cross in agonizing pain, he chooses not to beckon for his Father's angels to rescue him.

g. In the light of these instances, it can be said that even Jesus had free-will, just like Adam and Eve did back in the Garden of Eden. But unlike them, he was sure to align his will at all points during his brief life, along that of his Father's will.

\subsubsection{The Exodus of the Children of Israel}

The period following the settlement of Jacob's family in Egypt and Joseph's death, was marked by a phase of rapid population growth of their community. From an initial strength of seventy, they grew to millions and a new Pharaoh who did not know Joseph or what he had done for Egypt, became fearful of a possible hostile takeover. He began a reign of oppression and terror, turning the Hebrew people into slaves. God had foretold this event to Abraham in a dream, that his descendants would suffer much at the hands of a foreign nation and that after 400 years of slavery they would 
return to Canaan. Moses was the man to set them free from Pharaoh's bondage and later Joshua led them into the Promised Land. The interesting thing to note about the Exodus was its duration, which spanned about 40 years. The journey by foot from Egypt to Canaan should have taken, by most estimates, much less than a month to cover. Bible scholars agree that the reason for its protraction was their own obstinacy and tendency to use their free-will to grumble and complain against God and actively pursue the things $\mathrm{He}$ specifically told them not to.

\subsubsection{End-Times Prophecies Concerning the World}

The book of Genesis (the first book of the Bible), describes the grim fall of man and his permanent banishment from a paradise like state of existence in the garden of Eden. The book of Revelation (the last book of the Bible), speaks of a time of bliss that is yet to come, wherein the lion shall lie down beside the lamb and there shall be no more darkness or sickness or pain or tears or death. In other words, a Paradise once lost, restored again. Looking at the current state of the world and all of the past states it has gone through, one can't help but wonder how such an age can ever come to be. However, the Probabilistic Calculus that is developed in $\S 3$ and $\S 4$ of this paper, shows that the only ingredient needed is sufficient time and the world will make the transition.

\section{Central Thesis}

\subsection{A Theological Proposal for the Origin of Free-Will}

In the Biblical Story of Creation, God says "Let us make man in our Image" (Genesis 1:26). Another translation puts it this way, "Let us make man in our likeness". This is a mysterious verse. How can man be anything like God? What qualities do God and man share in common? God is omnipotent, omnipresent and omniscient. Human beings clearly have none of these qualities. So, what precisely did God mean by creating man in His likeness? It is proposed here, that there are two special gifts granted exclusively to man by his Creator, which make him just like Him. First, is the capacity to create things and second, is the capacity for free-will. The focus of this essay shall be on the latter.

\subsection{Theological Determinism}

This doctrine holds that every event in the world is preordained or predestined to happen by virtue of a transcendent agent's will or omniscience. This transcendent agent is God.

\subsection{Bridging Theological Determinism and Metaphysical Libertarianism}

If theological determinism is true, how then can free-will be possible? The explanation given below reconciles theological determinism (God's Omniscience) with an agent's free will and forms the basis of a novel proposal for Theological Compatibilism. God is indeed omniscient in all matters, particularly in regards to the gamut of all possibilities that an agent's free-will can choose from. However, He does not interfere with the choices made by the agent. That is, He does not prevent or coerce an agent to adopt any particular course of action. Rather, the agent is free to choose any course of action he pleases. Having said this, it should also be understood that there are certain events in an agent's existence that are predetermined to happen and cannot be evaded. These are called Determined Events. Every event that is not a Determined Event, is a Random Event. In the space of all possible events, a given course of actions leads an agent from one Determined Event to the next Determined Event, via a series of causally linked Random Events. The course of actions forms the trajectory of the Agent's existence through the space of all possible events. The multitude of different trajectories joining any two successive Determined Events in that space, can be thought of as an index for the Will's freedom. For the purpose of analogy, consider the game of tic tac toe or chess involving two players. God being omniscient, possesses the full knowledge of every possible game that can be played between them, which is a finite number for both games (although an extremely large number in the case of chess). The final outcome for any game will be one player wins, or both players draw. If each possible game, defined as a sequence of chosen moves, is considered a trajectory through the space of all possible sequence of moves, then there will be three bundles of trajectories that converge on three possible Determined Events: (i) player-1 wins, (ii) player-2 wins, (iii) draw. Though God can see the end from the beginning, He does not influence any player to choose a particular game plan to follow, but instead allows their free-will to operate and thus lead to a destined outcome. The above description somewhat resembles the Principle of Quantum Superposition, where different potentialities can co-exist in superposition, until the collapse of the wavefunction occurs by an act of observation. God sees the entire universe in a state of one big superposition of all possibilities. He also has full knowledge of every possible final outcome for the collapse of the wavefunction. However, it is not His act of observation that triggers the wavefunction to collapse, but our use of free-will.

\subsection{Summary of Thesis}

Now that the different views of various disciplines have been explored and the principal (Compatibilist) thesis of this essay presented, the underlying motivation may be stated: "It is logically erroneous or at least unnecessary to settle for the stance that the twin notions of determinism and free-will are incompatible." Using the Mathematical Theory of Probability, it is rigorously demonstrated how determinism and free-will can be meshed together to form inseparable parts of a whole, analogous to the two sides of a coin that make up the coin. In other words, it aims for and successfully accomplishes the task of performing a synthesis of the two opposed perspectives into a single, indivisible philosophical paradigm.

\section{The Random Walk Model}

\subsection{Operational Definitions}

1. Agent: One that is endowed with the power of free-will. 
2. Field: An agent's existence with all its potentialities is represented by a 2D spatial plane.

3. Event: A geometric point in the field.

4. Determined Event: An event that is pre-assigned and inescapable.

5. Random Event: An event that depends on free-will and is evitable.

6. Free-will: The total number of possibilities that emerge from an event.

7. Action: A freely made decision that leads an agent to the next event.

\subsection{Notational Propositions}

1. Step: Each action taken is represented by a short line of a fixed length with an arrow head marking the direction of progress through the field.

2. Station: An event in the field to which each step leads an agent. There are three types of stations in the field, namely a Start station, an End station and an Intermediary station. The names of these stations signify their relative positions in the field.

\subsection{Postulates}

1. For every event in the field, the available potential actions from which to choose, carry equal probability a priori.

2. Each step taken in the field is independent of the preceding step.

\subsection{Theory}

Let $\mathrm{A}$ be a start station and $\mathrm{B}$ be an end station in the field $\mathrm{F}$ (see Figure 2), which represents two determined events. At each intermediary station in the field $(1,2,3 \ldots \mathrm{N}-1)$, starting from station A, a step is drawn when an action is taken. These stations represent random events.

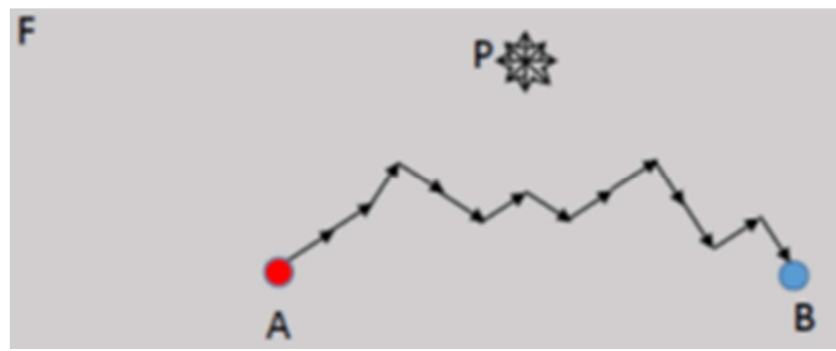

Figure 2. An example of a random walk journey from start station $A$ to end station $B$ in the field $F$.

The equal probability a priori postulate implies that a simple reciprocal of free-will at each event will yield the probability for choosing any particular action at that point in the field.

$P(A \rightarrow 1)=\frac{1}{n_{1}} ; P(1 \rightarrow 2)=\frac{1}{n_{2}} ; P(2 \rightarrow 3)=\frac{1}{n_{3}} ; \ldots P(N-1 \rightarrow B)=\frac{1}{n_{N}}$

Where $n_{1}, n_{2}, n_{3}, \ldots, n_{N}$ denote the free-wills at stations $\mathrm{A}$, $1,2,3, \ldots \mathrm{N}-1$ in the field F, respectively. In the Theory of Probability, the Law of Multiplication holds that the probability of the joint occurrence of independent events is equal to the product of the individual probabilities of those events. Therefore, if we apply this law to our current context after invoking the second postulate that each step taken in the field is independent of the preceding step, then it logically follows that the probability of a particular trajectory $A \rightarrow B$ in the field, is given by:

$$
\begin{gathered}
P(A \rightarrow B)=P(A \rightarrow 1) \cdot P(1 \rightarrow 2) \cdot P(2 \rightarrow 3) \ldots \ldots P(N-1 \rightarrow B) \\
P(A \rightarrow B)=\frac{1}{n_{1} \cdot n_{2} \cdot n_{3} \ldots n_{N}}=\prod_{i=1}^{i=N} \frac{1}{n_{i}}
\end{gathered}
$$

This is the general equation defining the probability of a given path through the field F. For the purpose of illustration, say that the free-will at each point in the field is fixed and equal to 4 which can be pictorially represented as the directional options: up, down, right and left (see Figure 3). Then, since $n_{1}=n_{2}=n_{3}=\cdots=n_{N}=4$, the above equation for $\mathrm{N}$ steps collapses down to:

$$
P(A \rightarrow B)=\frac{1}{4^{N}}
$$

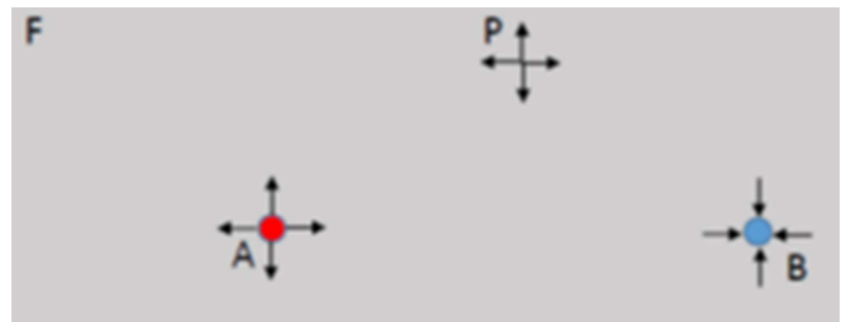

Figure 3. An example of a random walk journey wherein the agent can choose from only four possibilities at any point in the field $F$.

Consider now three concrete cases, where it takes a varied number of steps to make the voyage from point $A$ to point $B$ in the field: 10 steps, 20 steps and 30 steps.

$$
\begin{gathered}
\text { For } \mathrm{N}=10 \text { steps, } P_{1}(A \rightarrow B)=\frac{1}{4^{10}} \\
\text { For } \mathrm{N}=20 \text { steps, } P_{2}(A \rightarrow B)=\frac{1}{4^{20}} \\
\text { For } \mathrm{N}=30 \text { steps, } P_{3}(A \rightarrow B)=\frac{1}{4^{30}} \\
\therefore P_{1}(A \rightarrow B)>P_{2}(A \rightarrow B)>P_{3}(A \rightarrow B)
\end{gathered}
$$

This would mean that the probability of a path diminishes as the inverse power of the number of steps necessary to move from A to B. A corollary that follows is that the probability of a given path would tend to zero (i.e. an impossible path) as the number of steps needed to move from $A$ to $B$ in the field increased indefinitely. Formally stated,

$$
\operatorname{limit}_{N \rightarrow \infty} P(A \rightarrow B)=0
$$

This is however a limiting case and can be ignored since it would require an indefinite amount of time to cover an indefinite number of steps. For any two arbitrary points A and 
B within the field and a prescribed step size it is conceivable that only a finite number of steps would be necessary to make the journey from A to B within a finite amount of time. It can be readily shown that this probabilistic framework can accommodate both determinism and free-will into a coherent philosophical system, wherein both contraries operate in collusion.

\subsection{Concretizing the Random Walk Model}

Let us say that the agent with free-will is a man. Then his life is represented by the field $\mathrm{F}$ and every choice he makes is represented by a step that moves him from one station to the next. If Events A and B be the start and end stations of his life (not necessarily representing his birth and death, but rather any two conspicuous events in between), then determinism mandates that his trajectory must pass through $\mathrm{B}$ within his lifespan. And free-will mandates that there are an infinite number of possible step-wise routes that can be chosen by the agent to move from A to B. In other words, he is free to choose from amongst the infinity of possibilities, a particular path. It should be noted that this same luxury of choice does not extend to the end points $\mathrm{A}$ and $\mathrm{B}$ which are pre-determined, pre-assigned, unchangeable, inevitable, inescapable events. In the language of non-linear dynamical systems, the points $\mathrm{A}$ and $B$ can be said to be points of unstable equilibrium (repulsion) and stable equilibrium (attraction), respectively. In table 1, the events A and B for each of the examples listed in $\S 1.7$ are identified.

\subsection{Augmenting the Random Walk Model}

The Random Walk Model can be augmented in two aspects. The first concerns the temporal aspect of an agent's progression through the Field, which is dealt with only implicitly in the original model. In order to make the time-factor explicit, the 2D spatial Field F must be extended to a 3D space-time Field by introducing a perpendicular time component in the decision-making process (see Figure 4). The start station A and end station B would then be defined by three co-ordinates each, two of space and one of time. Consequently, the trajectory of an agent would resemble an ascending staircase like trace. The projection of this path onto the $\mathrm{XY}$ plane is equivalent to the previous $2 \mathrm{D}$ treatment depicted in Figures $2 \& 3$, provided that the Actions are taken in equal time intervals. Since time always progresses in the forward direction (pointing upwards in the diagram), the Steps at each point in the 3D Field F, are bounded to the circular base of a right cone with semi-vertical angle $\theta<90^{\circ}$ and long axis parallel to the Time axis (see Figures $5 \& 6$ ). Note that the projection of point B into the XY-plane, is fixed. However, the position of point B in the XYT-space is variable, depending on how soon the Agent makes the transit from A to B.

The second aspect concerns the rules for mapping an Agent's Action to the precise direction and size of a Step, which is again not made explicitly clear in the original model. The rule for direction can be established if at any given point in the Field, there are a set of Actions that are directed towards Event B (call them destinophilic actions) and a set of Actions that are directed away from Event B (call them destinophobic actions). From a religious perspective, the former actions are those that are in alignment with God's will and the latter actions are those that are in opposition to God's will. By aligning free-will in perfect accord with God's will, the shortest trajectory towards B can be traversed (see Figures $7 \& 8$ ).

Finally, the size of a Step can be determined if we assume the speed of transit to be the same along any chosen trajectory. Let $\Delta s$ units of distance be the step size, taken in $\Delta t$ units of time. And say that it takes $\tau$ units of time to traverse the entire length of the chosen trajectory $A \rightarrow B$, with a total of $n$ steps. If $v$ be the uniform speed of transit, then we can say:

$$
\begin{gathered}
\frac{\Delta s}{\Delta t}=\frac{n \cdot \Delta s}{\tau}=v \\
\Rightarrow \Delta s=\frac{v \cdot \tau}{n}
\end{gathered}
$$$$
\frac{\text { Step Size }}{\text { Time Interval }}=\frac{\text { Total Path Length }}{\text { Total Time of Transit }}=\text { Speed of Transit }
$$

From this, we see that the step size depends on:

i. Total number (n) of Actions taken to make the journey from A to B,

ii. Rapidity (v) of transit from A to B,

iii. Time of transit $(\tau)$ from $A$ to $B$.

While $v$ is arbitrary, $\mathrm{n}$ and $\tau$ can be known only post hoc, once the journey $A \rightarrow B$ has been completed. Also note, from Figure 6, the semi-vertical angle of the Decision Cone is equal to the inverse tangent of the speed of transit:

$$
\theta=\tan ^{-1}(v)
$$

\subsection{Remarks}

$$
\text { Take, } v=1 \text {, then } \theta=45^{\circ} \text { and } \Delta s=\Delta t=\tau / \mathrm{n}
$$

The computational parameters $\mathrm{n}$ and $\tau$ can then be used to tailor make the Random Walk Model, to suit the trajectory of any particular Agent.

Table 1. Applications of the Random Walk Model.

\begin{tabular}{lll}
\hline Agent & A & B \\
\hline Life of Oedipus & $\begin{array}{l}\text { The King of Thebes, was told by an oracle that his new born son would } \\
\text { grow up to one day kill him, take his throne and marry his wife. }\end{array}$ & $\begin{array}{l}\text { Oedipus becomes the new King of Thebes after killing } \\
\text { his father and marrying his mother }\end{array}$ \\
Lives of Adam and Eve & $\begin{array}{l}\text { God warned that the day they (Adam and Eve) eat from the forbidden } \\
\text { tree, they would die } \\
\text { God promises Abraham that He would make him the Father of many }\end{array}$ & $\begin{array}{l}\text { More than 51\% of the world population today belong to } \\
\text { nations. }\end{array}$ \\
nife of Abraham & \begin{tabular}{l} 
namamic Religion and refer to him as father \\
\hline
\end{tabular}
\end{tabular}




\begin{tabular}{|c|c|c|}
\hline Agent & $\mathbf{A}$ & $\mathbf{B}$ \\
\hline Life of Joseph & $\begin{array}{l}\text { Joseph has two dreams where he sees himself exalted above the rest of } \\
\text { his family }\end{array}$ & $\begin{array}{l}\text { Abraham in their traditions } \\
\text { Joseph becomes Prime Minister of Egypt - the second } \\
\text { most powerful man in the Ancient World }\end{array}$ \\
\hline Life of Gideon & $\begin{array}{l}\text { Angel proclaims to Gideon that he will be the one to lead the Israelites } \\
\text { to victory in battle }\end{array}$ & Gideon defeats the Midianites \\
\hline Life of Jesus & $\begin{array}{l}\text { It was foretold by the Prophets that the Messiah would come and that } \\
\text { he would suffer much and be wounded for man's transgressions. }\end{array}$ & $\begin{array}{l}\text { Christ is beaten, whipped and crucified. He then rises up } \\
\text { from death three days later }\end{array}$ \\
\hline End Time Prophecies & Fall of Man in the Garden of Eden & Paradise will be Restored one day soon \\
\hline
\end{tabular}

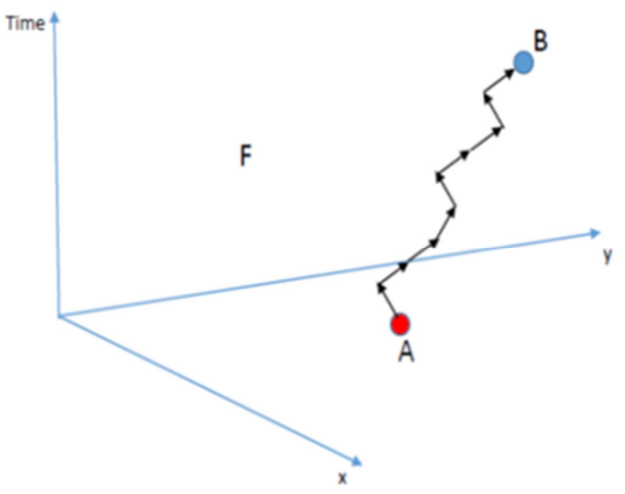

Figure 4. Time factor is incorporated into the original Random Walk Model.

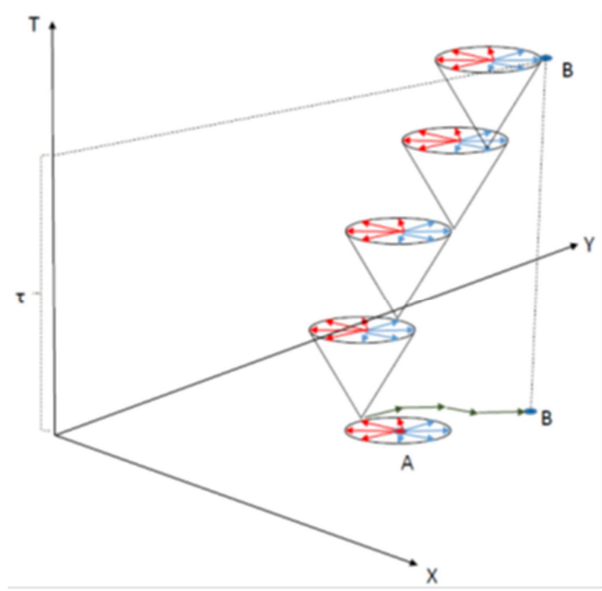

Figure 5. Each point $P$ in the $3 D$ space-time field $F$ corresponds to a cone with a fixed circular base.

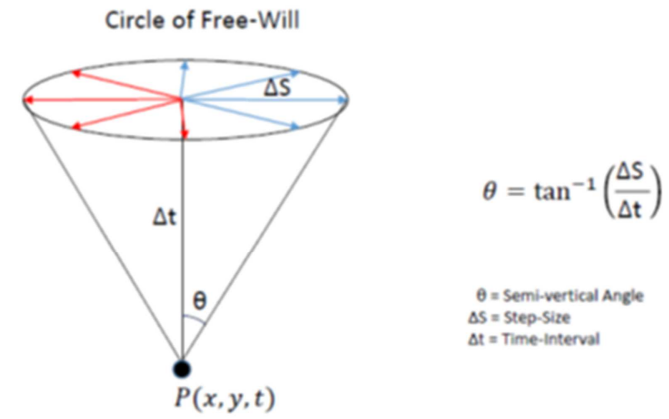

Decision Cone in 3D Space-time Field

Figure 6. Decision Cone corresponding to a random point $P(x, y, t)$ in the $3 D$ space-time field $F$.

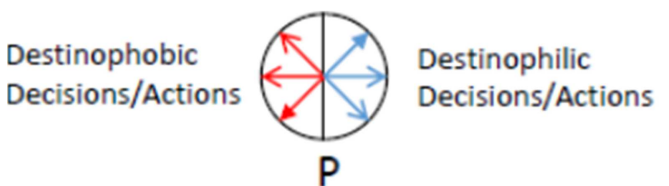

Figure 7. Two types of Actions form the circular base of the Decision Cone.

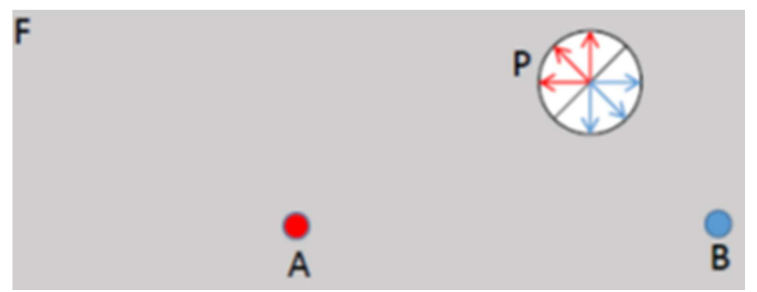

Figure 8. Actions that lead an agent towards $B$ are in blue and those away from $B$ in red.

\section{The Probabilistic Vector Field Model}

\subsection{Operational Definitions}

1. Agent: One that is endowed with the power of free-will.

2. Field: An agent's existence with all its potentialities is represented by a $2 \mathrm{D}$ spatial plane.

3. Event: A geometric point in the field.

4. Determined Event: An event through which the trajectory of an agent's existence must pass through.

5. Random Event: An event through which the trajectory of an agent's existence may pass through.

6. Free-will: The freedom to choose a particular trajectory.

\subsection{Propositions}

1. Every random event in the field $\mathrm{F}$ is associated with a finite probability of finding the agent there, which can be computed using a special Probability Function Formula.

2. The two determined events $A$ and $B$ are associated with a minimum probability (zero) and a maximum probability (unit), respectively.

3. There exists a gradient of the probability function for all random events in the field $F$. The gradient of the probability function is zero at both the determined events $\mathrm{A}$ and $\mathrm{B}$.

4. The gradient of the Probability Function is called a Probability Vector Function. The divergence of this Vector Function is positive at the Determined Event A and negative at the Determined Event B. That is, the 
former acts as a Source and the latter acts as a Sink in the Probability Vector Field.

\subsection{Postulate}

The Agent courses a trajectory from A to B through the Field $\mathrm{F}$, along the direction of the gradient of the probability function at each point in F. The magnitude of the probability function increases from zero at $\mathrm{A}$ to unit at $\mathrm{B}$.

\subsection{Theory}

The Probability Function that satisfies all the above definitions, propositions and postulate is (see figure 9):

$$
P(x, y)=\frac{1}{\sqrt{2}} x \cdot e^{\left(-x^{2}-y^{2}+\frac{1}{2}\right)}+\frac{1}{2}
$$

Applying the gradient operator to the above,

$$
\begin{gathered}
\boldsymbol{\nabla} P(x, y)=(1 / \sqrt{2})\left(1-2 x^{2}\right) \cdot e^{\left(-x^{2}-y^{2}+1 / 2\right)} \hat{\boldsymbol{\imath}} \\
-\sqrt{2} x y \cdot e^{\left(-x^{2}-y^{2}+1 / 2\right)} \hat{\boldsymbol{\jmath}}
\end{gathered}
$$

Again, $\forall(x, y) \in \mathbb{R}^{2} \exists \nabla P(x, y) \in \mathbb{R}$ and $\nabla P(x, y)$ is zero at both points $A(-1 / \sqrt{2}, 0)$ and $B(1 / \sqrt{2}, 0)$. That is, $\nabla P(-1 / \sqrt{2}, 0)=0=\nabla P(1 / \sqrt{2}, 0)$. Thus, Proposition-3 is satisfied. By the first part of Proposition-4, the Probability Vector Function is defined as the Gradient of the Probability (Scalar) Function $P(x, y)$. That is,

$$
\vec{P}=\nabla P(x, y)
$$

The quiver plot of the Probability Vector Function is shown in figure 10. The expression for its Divergence is,

$$
\boldsymbol{\nabla} \cdot \vec{P}=2 \sqrt{2} x\left(x^{2}+y^{2}-2\right) e^{\left(-x^{2}-y^{2}+1 / 2\right)}
$$

At point $A(-1 / \sqrt{2}, 0), \boldsymbol{\nabla} \cdot \vec{P}=3>0$ and at point $B(1 /$ $\sqrt{2}, 0), \boldsymbol{\nabla} \cdot \vec{P}=-3<0$. This implies that the Determined Events A and B are points of divergence and convergence, respectively in the Probability Vector Field. Thus, the second part of Proposition-4 is satisfied.

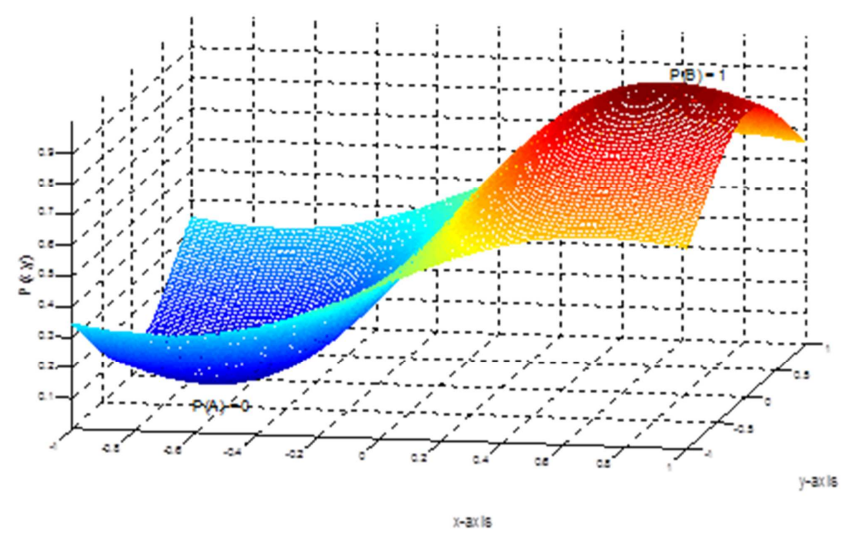

Figure 9. $3 D$ Plot of $P(x, y)$.

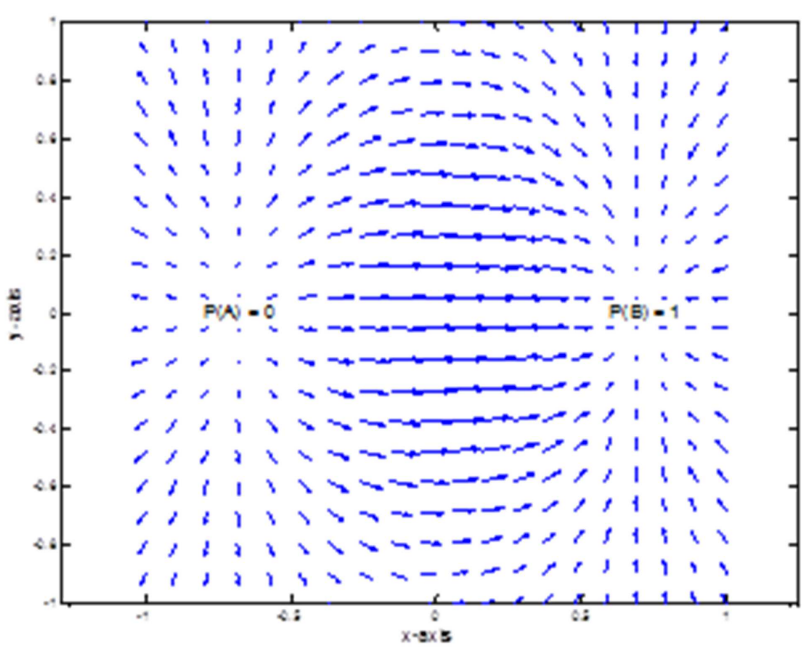

Figure 10. Quiver plot of $P(x, y)$.

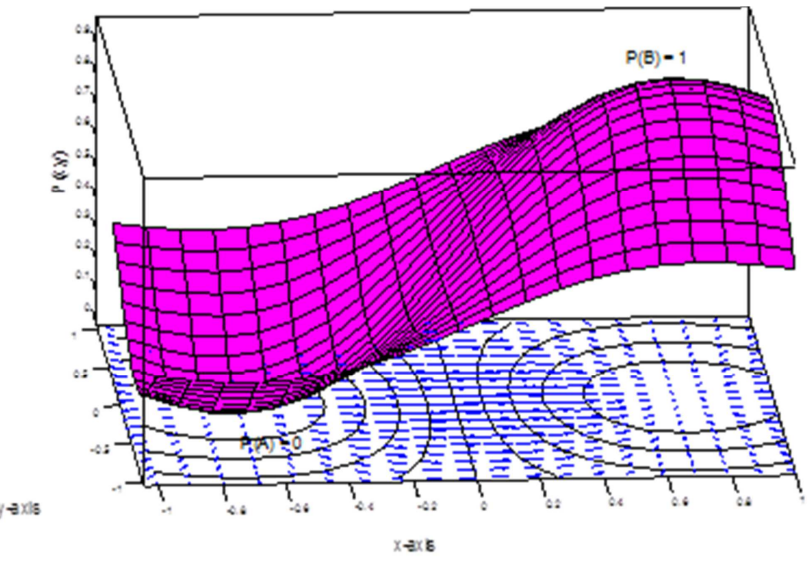

Figure 11. Combined $3 D$ plot \& Quiver plot of $P(x, y)$.

\subsection{Incorporating Time into the Probabilistic Vector Field Model}

The Probabilistic Vector Field Model developed so far, does not make an explicit inclusion of the Agent's time of transit through the Field F. Inorder to make the inclusion, it is first necessary to state a theorem from Vector Calculus: "A vector field is said to be conservative if there exists a scalar field such that, the vector field can be expressed as the gradient of that scalar field." The principal property of such a conservative vector field, is that its line integral between two extreme points, is the same regardless of the chosen path of integration, i.e. its line integral is Path Independent and is equal to the difference in the values of the scalar field at the two extreme points. By Propositions $3 \& 4$, the vector field $\vec{P}$ and the scalar field $P(x, y)$, satisfy this theorem. Hence, the line integral of $\vec{P}$ between the points A and B can be written as follows:

$$
\int_{A}^{B} \vec{P} \cdot \overrightarrow{d r}=P(B)-P(A)
$$

By Proposition-2, $P(A)=0$ and $P(B)=1$. Therefore, the line integral between $A$ and $B$ is of unit magnitude. Now, consider a random point $Q(x, y)$ in the Field $\mathrm{F}$, that lies on a 
given trajectory between A and B. Then the line integral of $\vec{P}$ between the points $\mathrm{A}$ and $\mathrm{Q}$ is:

$$
\int_{A}^{Q} \vec{P} \cdot \overrightarrow{d r}=P(Q)-P(A)
$$

\subsection{Proposition-5}

The Time of Transit of the Agent between any two points $\mathrm{C}$ and $\mathrm{D}$ in the Field $\mathrm{F}$, is directly proportional to the line integral of $\vec{P}$ between those points.

$$
\Delta t_{C D} \propto \int_{C}^{D} \vec{P} \cdot \overrightarrow{d r}
$$

Let the time at which the Agent's journey begins from $A$ be $t_{A}=0$ and the time of arrival at $\mathrm{B}$ be $t_{B}=\tau$. Then using Propositions $2 \& 5$, it follows that,

$$
\begin{gathered}
\frac{\text { Time of Transit } A \rightarrow Q}{\text { Time of Transit } A \rightarrow B}=\frac{\text { Line Integral } A \rightarrow Q}{\text { Line Integral } A \rightarrow B} \\
\Rightarrow \frac{\Delta t_{A Q}}{\Delta t_{A B}}=\frac{\int_{A}^{Q} \vec{P} \cdot \overrightarrow{d r}}{\int_{A}^{B} \vec{P} \cdot \overrightarrow{d r}} \Rightarrow \frac{t_{Q}-t_{A}}{t_{B}-t_{A}}=\frac{P(Q)-P(A)}{P(B)-P(A)} \\
\Rightarrow \frac{t_{Q}-0}{\tau-0}=\frac{P(Q)-0}{1-0} \Rightarrow t_{Q}=P(Q) \cdot \tau \\
\Rightarrow t(x, y)=P(x, y) \cdot \tau \\
\Rightarrow t(x, y)=\left(\frac{1}{\sqrt{2}} x \cdot e^{\left(-x^{2}-y^{2}+\frac{1}{2}\right)}+\frac{1}{2}\right) \tau
\end{gathered}
$$

\subsection{Proposition-6}

The Time of Transit of the Agent between any two points $C$ and $\mathrm{D}$ in the Field $\mathrm{F}$ is directly proportional to the difference in the Probabilities of finding the Agent at those points.

$$
\Delta t_{C D} \propto \Delta P_{C D}
$$

$$
\begin{array}{r}
\Rightarrow \frac{\text { Time of Transit } A \rightarrow Q}{\text { Time of Transit } A \rightarrow B} \\
=\frac{\text { Difference of Probabilities } A \rightarrow Q}{\text { Difference of Probabilities } A \rightarrow B} \\
\Rightarrow \frac{t_{Q}-t_{A}}{t_{B}-t_{A}}=\frac{P(Q)-P(A)}{P(B)-P(A)} \Rightarrow \frac{t_{Q}-0}{\tau-0}=\frac{P(Q)-0}{1-0} \\
\Rightarrow t_{Q}=P(Q) \cdot \tau \Rightarrow t(x, y)=P(x, y) \cdot \tau \\
\Rightarrow t(x, y)=\left(\frac{1}{\sqrt{2}} x \cdot e^{\left(-x^{2}-y^{2}+\frac{1}{2}\right)}+\frac{1}{2}\right) \tau
\end{array}
$$

\subsection{Proposition-7}

The instantaneous time rate of change of Probability is a constant, for every possible trajectory between $\mathrm{A}$ and $\mathrm{B}$, as the Agent traverses through the Field F.

$$
\begin{gathered}
\frac{d(P(x, y))}{d t}=\text { constant for every path between } A \rightarrow B \\
\Rightarrow \Delta t \propto \Delta P \\
\Rightarrow \frac{t_{Q}-t_{A}}{t_{B}-t_{A}}=\frac{P(Q)-P(A)}{P(B)-P(A)} \Rightarrow \frac{t_{Q}-0}{\tau-0}=\frac{P(Q)-0}{1-0} \\
\Rightarrow t_{Q}=P(Q) \cdot \tau \Rightarrow t(x, y)=P(x, y) \cdot \tau \\
\Rightarrow t(x, y)=\left(\frac{1}{\sqrt{2}} x \cdot e^{\left(-x^{2}-y^{2}+\frac{1}{2}\right)}+\frac{1}{2}\right) \tau
\end{gathered}
$$

\subsection{Remarks}

Clearly, Propositions 5, $6 \& 7$ are equivalent statements that validate each other, since the same result can be drawn from each of them, independently:

$$
t(x, y)=\left(\frac{1}{\sqrt{2}} x \cdot e^{\left(-x^{2}-y^{2}+\frac{1}{2}\right)}+\frac{1}{2}\right) \tau
$$

The above formula, defines the instant of time $t$ at which the Agent can be found at a particular point $(x, y)$ along the chosen trajectory $A \rightarrow B$ in the 2D Field F. Or alternatively, it defines the Space-time point $(x, y, t)$ of the Agent in the 3D field $F$. If $B$ represents a determined event that is to occur at a particular time $\tau$, then regardless of which pathway the Agent chooses by virtue of free-will, he will always arrive at $\mathrm{B}$, at the appointed time $\tau$. Thus, in the Probabilistic Vector Field Model, both the position of the determined event B in the field $F$ and the time of the Agent's arrival there $\tau$, are fixed. But in the Random Walk Model, only the position of B in the field F is fixed, while the time of arrival $\tau$ is variable.

\section{Final Conclusion}

In quintessence, a merger between determinism and free-will is mathematically plausible, upon accepting the proposition that "it's the paths that one can choose, the end points are already chosen". That is, though a person can make free and independent choices in life, the final consequence of the series of choices made are pre-determined. The question which naturally follows from this is: "Does God make use of a similar 'Probabilistic Calculus for the World' by designating some events as determined and others random?" Listed below, are a few verses from the New International Version of the Bible that answers this question in the affirmative and provides the philosophical impetus for the two mathematical models forwarded herein, namely the Random Walk Model and the Probabilistic Vector Field Model.

There is a time for everything, and a season for every activity under the heavens (Ecclesiastes 3:1).

$\mathrm{He}(\mathrm{God})$ has made everything beautiful in its time. He has also set eternity in the human heart; yet no one can fathom what God has done from beginning to end (Ecclesiastes 3:11).

A person's days are determined. You (God) have decreed the number of his months and have set limits he cannot exceed. (Job 14:5). 
My times are in your hands (Psalm 31:15).

I (God) choose the appointed time. (Psalm 75:2).

For the revelation awaits an appointed time; it speaks of the end and will not prove false. Though it linger, wait for it; it will certainly come and will not delay (Habakkuk 2:3).

From one man, He (God) made all the nations, that they should inhabit the whole earth; and He marked out their appointed times in history and the boundaries of their lands (Acts 17:26).

It is not for you to know the times or dates the Father has set by His own authority (Acts 1:7)

\section{Mathematical Appendix}

\subsection{Derivation of the Expression for Probability Function $P(x, y)$}

Consider the two-variable function $z=f(x, y)$ defined as follows and whose plot is shown in figure 12:

$$
z=f(x, y)=x \cdot e^{\left(-x^{2}-y^{2}\right)}
$$

If a hypothetical ball were allowed to roll down from the top of the mountain (labelled A), it would end up at the bottom of the valley (labelled B) after coursing a certain trajectory (drawn as a series of pink arrows). No matter how the ball is released from $\mathrm{A}$, it will always end up at $\mathrm{B}$. The function $f(x, y)$ would therefore, form the ideal candidate to model both Determinism and Free-Will. The fixed points A and B can represent Determined Events and the variable trajectories from A to B can represent Free-Will. Also the Theory of Probability can be introduced, by designating zero probability (minimum) to point $\mathrm{A}$ and unit probability (maximum) to point B, for finding the Agent at these points. Consequently, every other point will be associated with an intermediate probability, lying between zero and unit.

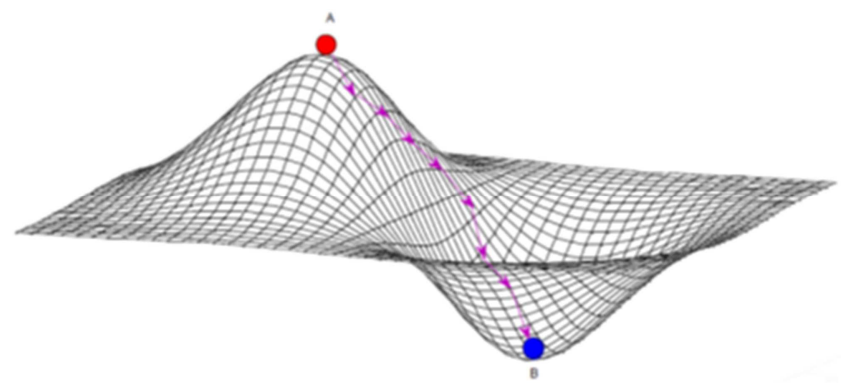

Figure 12. Mountain-Valley metaphor.

In order to derive $P(x, y)$ (the probability of finding the Agent at a point $(x, y))$ from $f(x, y)$, first the minimum and maximum values of the latter function must be calculated. Then the Normalization Formula is to be used, to constrain $f(x, y)$ within the range 0 to 1 .

Starting with our original function $f(x, y)$,

$$
f(x, y)=x \cdot e^{\left(-x^{2}-y^{2}\right)}
$$

Differentiating $f(x, y)$ partially w.r.t $x$ and partially w.r.t $y$,

$$
\begin{gathered}
f_{x}=\frac{\partial f}{\partial x}=\left(1-2 x^{2}\right) \cdot e^{\left(-x^{2}-y^{2}\right)} \\
f_{y}=\frac{\partial f}{\partial y}=-2 x y \cdot e^{\left(-x^{2}-y^{2}\right)}
\end{gathered}
$$

Critical points are found by setting by setting,

$$
\begin{gathered}
f_{x}=0 \Rightarrow x= \pm \frac{1}{\sqrt{2}} \\
f_{y}=0 \Rightarrow x=0 \& y=0
\end{gathered}
$$

Therefore, the Critical points are:

$$
\left(\frac{1}{\sqrt{2}}, 0\right),\left(-\frac{1}{\sqrt{2}}, 0\right),(0,0)
$$

Differentiating $f_{x}$ and $f_{y}$ partially w.r.t $x$ and partially w.r.t $y$, respectively

$$
\begin{aligned}
& f_{x x}=\frac{\partial^{2} f}{\partial x^{2}}=-2 x\left(3-2 x^{2}\right) \cdot e^{\left(-x^{2}-y^{2}\right)} \\
& f_{y y}=\frac{\partial^{2} f}{\partial y^{2}}=-2 x\left(1-2 y^{2}\right) \cdot e^{\left(-x^{2}-y^{2}\right)}
\end{aligned}
$$

Differentiating $f_{x}$ partially w.r.t $y$,

$$
f_{x y}=\frac{\partial f_{x}}{\partial y}=-2 y\left(1-2 x^{2}\right) \cdot e^{\left(-x^{2}-y^{2}\right)}
$$

Discriminant Function is given by,

$$
\begin{gathered}
D=f_{x x} \cdot f_{y y}-f_{x y}{ }^{2} \\
\Rightarrow D=4\left[x^{2}\left(3-2 x^{2}\right)\left(1-2 y^{2}\right)\right. \\
\left.-y^{2}\left(1-2 x^{2}\right)^{2}\right] \cdot e^{-2\left(x^{2}+y^{2}\right)}
\end{gathered}
$$

The Discriminant Function is evaluated for the three different critical points and is tabulated in table 2 .

Table 2. Calcualtion of local maxima and local minima for $f(x, y)$.

\begin{tabular}{llll}
\hline Critical Point $(\boldsymbol{a}, \boldsymbol{b})$ & $\left(\frac{\mathbf{1}}{\sqrt{2}}, \mathbf{0}\right)$ & $\left(-\frac{\mathbf{1}}{\sqrt{2}}, \mathbf{0}\right)$ & $(\mathbf{0}, \mathbf{0})$ \\
\hline$f_{x x}$ & $-2 \sqrt{2} \cdot e^{-\frac{1}{2}}$ & $2 \sqrt{2} \cdot e^{-\frac{1}{2}}$ & 0 \\
$f_{y y}$ & $-\sqrt{2} \cdot e^{-\frac{1}{2}}$ & $\sqrt{2} \cdot e^{-\frac{1}{2}}$ & 0 \\
$f_{x y}$ & 0 & 0 & 0 \\
$D(a, b)$ & $4 e^{-1}$ & $4 e^{-1}$ & 0 \\
Nature of $(a, b)$ & Local Maxima & Local Minima & Cannot say \\
\hline
\end{tabular}

Therefore, the values of $f(x, y)$ at the local maxima and local minima are,

$$
\begin{gathered}
f_{\text {max }}=f\left(\frac{1}{\sqrt{2}}, 0\right)=\frac{1}{\sqrt{2}} e^{-\frac{1}{2}} \\
f_{\text {min }}=f\left(-\frac{1}{\sqrt{2}}, 0\right)=-\frac{1}{\sqrt{2}} e^{-\frac{1}{2}}
\end{gathered}
$$

Now using the Normalization Formula, to constrain $f(x, y)$ within the range 0 to 1 , 


$$
\begin{aligned}
f_{\text {norm }} & =\frac{f(x, y)-f_{\min }}{f_{\max }-f_{\min }} \\
\Rightarrow f_{\text {norm }} & =\frac{x \cdot e^{\left(-x^{2}-y^{2}\right)}+\frac{1}{\sqrt{2}} e^{-\frac{1}{2}}}{\frac{1}{\sqrt{2}} e^{-\frac{1}{2}}+\frac{1}{\sqrt{2}} e^{-\frac{1}{2}}} \\
\Rightarrow f_{\text {norm }} & =\frac{1}{\sqrt{2}} x \cdot e^{\left(-x^{2}-y^{2}+\frac{1}{2}\right)}+\frac{1}{2}
\end{aligned}
$$

Defining our Probability Function as,

$$
P(x, y)=f_{\text {norm }}
$$

That is, the required expression for $P(x, y)$ is,

$$
P(x, y)=\frac{1}{\sqrt{2}} x \cdot e^{\left(-x^{2}-y^{2}+\frac{1}{2}\right)}+\frac{1}{2}
$$

\subsection{Derivation of the Expression for Probability Vector Function $\overrightarrow{\boldsymbol{P}}(\boldsymbol{x}, \boldsymbol{y})$}

We have found that the Probability Scalar Function is,

$$
P(x, y)=\frac{1}{\sqrt{2}} x \cdot e^{\left(-x^{2}-y^{2}+\frac{1}{2}\right)}+\frac{1}{2}
$$

The Gradient of $P(x, y)$ is defined as,

$$
\boldsymbol{\nabla} P(x, y)=\frac{\partial P}{\partial x} \hat{\boldsymbol{\imath}}+\frac{\partial P}{\partial y} \hat{\boldsymbol{\jmath}}
$$

Differentiating $P(x, y)$ partially w.r.t $x$ and $y$ separately,

$$
\begin{gathered}
\frac{\partial P}{\partial x}=\frac{1}{\sqrt{2}}\left(1-2 x^{2}\right) \cdot e^{\left(-x^{2}-y^{2}+\frac{1}{2}\right)} \\
\frac{\partial P}{\partial y}=-\sqrt{2} x y \cdot e^{\left(-x^{2}-y^{2}+\frac{1}{2}\right)}
\end{gathered}
$$

Therefore,

$$
\begin{aligned}
\nabla P(x, y) & =\frac{1}{\sqrt{2}}\left(1-2 x^{2}\right) \cdot e^{\left(-x^{2}-y^{2}+\frac{1}{2}\right)} \hat{\imath} \\
& -\sqrt{2} x y \cdot e^{\left(-x^{2}-y^{2}+\frac{1}{2}\right)} \hat{\jmath}
\end{aligned}
$$

From Proposition-4,

$$
\vec{P}=\nabla P(x, y)
$$

Hence the required expression for Probability Vector Function is,

$$
\vec{P}=\frac{1}{\sqrt{2}}\left(1-2 x^{2}\right) \cdot e^{\left(-x^{2}-y^{2}+\frac{1}{2}\right)} \hat{\imath}-\sqrt{2} x y \cdot e^{\left(-x^{2}-y^{2}+\frac{1}{2}\right)} \hat{\jmath}
$$

\section{NOTE:}

The Gradients of the Probability Scalar Function $P(x, y)$ can be shown to be zero at both the local minima and maxima, by substitution, At Local Minima $A\left(-\frac{1}{\sqrt{2}}, 0\right), \vec{P}(\mathrm{~A})=$ $\nabla P(A)=0 \hat{\imath}+0 \hat{\jmath}$. At Local Maxima $B\left(\frac{1}{\sqrt{2}}, 0\right), \vec{P}(B)=$ $\nabla P(B)=0 \hat{\imath}+0 \hat{\jmath}$. This can be interpreted to mean, that there is no preferred direction for the ball to roll down from the top of the hill located at $A\left(-\frac{1}{\sqrt{2}}, 0\right)$ in the $2 \mathrm{D}$ Field $\mathrm{F}$ and also no preferred direction for the ball to reach the bottom of the valley located at $B\left(\frac{1}{\sqrt{2}}, 0\right)$ either.

\subsection{Derivation of the Expression for the Divergence of the Probability Vector Function $\vec{P}(x, y)$}

The Divergence of $\vec{P}(x, y)$ can be calculated as follows,

$$
\nabla \cdot \vec{P}=\nabla \cdot(\nabla P)=\nabla^{2} P=\frac{\partial^{2} P}{\partial x^{2}}+\frac{\partial^{2} P}{\partial y^{2}}
$$

Differentiating $\frac{\partial P}{\partial x}$ and $\frac{\partial P}{\partial y}$ partially w.r.t $x$ and $y$, respectively

$$
\begin{aligned}
& \frac{\partial^{2} P}{\partial x^{2}}=-\sqrt{2} \cdot x\left(3-2 x^{2}\right) \cdot e^{\left(-x^{2}-y^{2}+\frac{1}{2}\right)} \\
& \frac{\partial^{2} P}{\partial y^{2}}=-\sqrt{2} \cdot x\left(1-2 y^{2}\right) \cdot e^{\left(-x^{2}-y^{2}+\frac{1}{2}\right)}
\end{aligned}
$$

Therefore, we get the required expression,

$$
\nabla \cdot \vec{P}=-\sqrt{2} \cdot x\left(4-2 x^{2}-2 y^{2}\right) \cdot e^{\left(-x^{2}-y^{2}+\frac{1}{2}\right)}
$$

The Divergence of $\vec{P}(x, y)$ at the Local Minima $A\left(-\frac{1}{\sqrt{2}}, 0\right)$ can be found by substitution,

$$
\nabla \cdot \vec{P}=3>0
$$

\section{$\Rightarrow$ Point $A$ acts as a Source in the Probability Vector Field}

The Divergence of $\vec{P}(x, y)$ at the Local Maxima $B\left(\frac{1}{\sqrt{2}}, 0\right)$ can be found by substitution,

$$
\nabla \cdot \vec{P}=-3<0
$$

$\Rightarrow$ Point $B$ acts as a Sink in the Probability Vector Field

\section{Acknowledgements}

Gloria in Excelsis Deo

I wish to thank my dear parents, Shweta, Prof. Sisir Roy (NIAS), Prof. SP Basavaraju (VTU), Prof. RI Sujith (IIT-M), Mr. Shoukat Ali sir (IHS), Pastor Johnson (Bethel AG), Mr. KK Kutty (IGNOU), Gabriel, Kashif, Xaver, Arnold and my department colleagues at EPCMS, for all the love, support and encouragement they've showered upon me.

\section{References}

[1] Pereboom, Derk (2001) Living without Free Will. Cambridge: Cambridge University Press.

[2] Kane, Robert (2003) Free Will: New Directions for an Ancient Problem. Malden, MA: Blackwell. 
[3] Saul Smilansky (2000) Free Will and Illusion, Oxford.

[4] McKenna, Michael and Coates, D. Justin "Compatibilism", The Stanford Encyclopedia of Philosophy (Winter 2018 Edition).

[5] Lewis, C. S. (1947). Miracles; a preliminary study.

[6] White, Graham, "Medieval Theories of Causation", The Stanford Encyclopedia of Philosophy (Summer 2018 Edition).

[7] Bohm, D. (2004). Causality and chance in modern physics. Routledge.

[8] B. Libet (1999). Do we have free-will? Journal of consciousness studies, 6(8-9), 47-57.

[9] S. Hameroff (2012). How quantum brain biology can rescue conscious free will. Frontiers in integrative neuroscience, 6, 93.
[10] S. Hameroff (1998). Quantum computation in brain microtubules? The Penrose-Hameroff 'Orch OR 'model of consciousness. Philosophical Transactions of the Royal Society of London. Series A: Mathematical, Physical and Engineering Sciences, 356(1743), 1869-1896.

[11] Popper, K. R., \& Eccles, J. C. (2012). The self and its brain. Springer Science \& Business Media.

[12] Chalmers, D. J. (2010). The character of consciousness. Oxford University Press.

[13] Kane, R. (Ed.). (2011). The Oxford handbook of free will. OUP USA.

[14] Oedipus: King of Thebes. Oxford University Press, American Branch, 1911. 